\title{
Article \\ Pattern of Use of Electronic Health Record (EHR) among the Chronically Ill: A Health Information National Trend Survey (HINTS) Analysis
}

\author{
Rose Calixte ${ }^{1, *(\mathbb{D}}$, Sumaiya Islam ${ }^{2}$, Zainab Toteh Osakwe ${ }^{3}$, Argelis Rivera ${ }^{4}$ and Marlene Camacho-Rivera ${ }^{5}(\mathbb{D})$ \\ 1 Department of Epidemiology and Biostatistics, SUNY Downstate Health Sciences University, \\ Brooklyn, NY 11203, USA \\ 2 CUNY School of Medicine, City College of New York, New York, NY 10031, USA; sislam011@csom.cuny.edu \\ 3 College of Nursing and Public Health, Adelphi University, Garden City, NY 11530, USA; \\ zosakwe@adelphi.edu \\ 4 Department of Medicine, Mount Sinai Icahn School of Medicine, New York, NY 10011, USA; \\ argelis.rivera@mountsinai.org \\ 5 Department of Community Health Sciences, SUNY Downstate Health Sciences University, \\ Brooklyn, NY 11203, USA; marlene.camacho-rivera@downstate.edu \\ * Correspondence: rose.calixte@downstate.edu
}

Citation: Calixte, R.; Islam, S.; Osakwe, Z.T.; Rivera, A.; Camacho-Rivera, M. Pattern of Use of Electronic Health Record (EHR) among the Chronically Ill: A Health Information National Trend Survey (HINTS) Analysis. Int. J. Environ. Res Public Health 2021, 18, 7254. https:// doi.org/10.3390/ijerph18147254

Academic Editors:

Irene Torres-Sanchez and Marie Carmen Valenza

Received: 4 June 2021

Accepted: 4 July 2021

Published: 7 July 2021

Publisher's Note: MDPI stays neutral with regard to jurisdictional claims in published maps and institutional affiliations.

Copyright: (c) 2021 by the authors. Licensee MDPI, Basel, Switzerland. This article is an open access article distributed under the terms and conditions of the Creative Commons Attribution (CC BY) license (https:// creativecommons.org/licenses/by/ $4.0 /)$

\begin{abstract}
Effective patient-provider communication is a cornerstone of patient-centered care. Patient portals provide an effective method for secure communication between patients or their proxies and their health care providers. With greater acceptability of patient portals in private practices, patients have a unique opportunity to manage their health care needs. However, studies have shown that less than $50 \%$ of patients reported accessing the electronic health record (EHR) in a 12-month period. We used HINTS 5 cycle 1 and cycle 2 to assess disparities among US residents 18 and older with any chronic condition regarding the use of EHR for secure direct messaging with providers, to request refills, to make clinical decisions, or to share medical records with another provider. The results indicate that respondents with multimorbidity are more likely to share their medical records with other providers. However, respondents who are 75 and older are less likely to share their medical records with another provider. Additionally, respondents who are 65 and older are less likely to use the EHR for secure direct messaging with their provider. Additional health care strategies and provider communication should be developed to encourage older patients with chronic conditions to leverage the use of patient portals for effective disease management.
\end{abstract}

Keywords: chronic conditions; patient portal; health communication

\section{Introduction}

Patient-physician communication, particularly patients' satisfaction with physicians' communication approaches, is important for better outcomes in patient-centered health care organizations [1,2]. Finding effective ways of maintaining communication between health care providers and patients outside of the health care organization is important for disease management and care coordination [1,2]. With legislation mandating the meaningful use of electronic health records (EHR), by $2015,98 \%$ of hospitals and $78 \%$ of private practices in the United States offered patient portals [3,4]. Patient portals also provide effective communication tools with the potential to increase patient engagement in self-care management. Patients can also use patient portals for prescription renewal, appointment management, checking lab results, and messaging their providers [5]. Therefore, the use of patient portals is an increasingly common approach in patient-centered care practices [1,2].

With the aging of the US population, certain diseases are becoming more prevalent [6]. Additionally, with people living longer, the prevalence of multimorbidity is also increasing [7-12]. Patients with multiple chronic conditions usually require a team of specialists 
for managing their conditions [13,14]. Maintenance of their treatment plans requires effective communication with patients and coordination of care among their team of providers to achieve better outcomes [15]. Prior research has shown that access to patient portals resulted in improved diabetes-related outcomes and adherence to hypertensive medication $[16,17]$. Additionally, a recent study of patients with chronic kidney disease (CKD) found that the use of EHR improves patient-centered outcomes such as CKD-specific knowledge, while reducing CKD-related stress [5]. The ongoing COVID-19 pandemic has accelerated the use of technologies such as patient portals for health care delivery $[18,19]$. Despite the increasing reliance on the use of technology for both preventive and follow-up care, some patients lack resources to engage effectively in telehealth [18].

Despite the proliferation of health-related internet use (HRIU) and the widespread use of the internet by the general population, disparities still exist in terms of access and use of internet for disease management [20-25]. Recent studies suggest that despite the increasing trend in the use of patient portals, the acceptability of patient portals in the general population remains unusually low [18]. Additionally, sociodemographic disparities exist in assessing patient portals as a tool for disease management and communication with providers [26-28]. A recent study on disparities in health-related internet content that focused on the noninstitutionalized population of the US assessed health information seeking behavior in three domains relevant to health communication (health care, health information-seeking, and user-generated content/sharing). The study indicated age, gender, race/ethnicity, education, and income related disparities across multiple domains of health communication [29].

Several studies have examined potential explanations for low EHR engagement, and HRIU more broadly, within racial and ethnic minority populations. A recent study which examined disparities in trust in sources of cancer-related health information among Hispanics in the US observed that older Hispanics had higher odds of trusting cancer information from a religious organization compared to younger Hispanics [30]. Another study of men with chronic conditions developed an eHealth usage score using seven domains of eHealth communication, which included EHR use [31]. The eHealth questions used to create the score asked whether respondents had done the following: used a computer, smartphone or other electronic means to (1) look for health information or medical information for yourself, (2) look for health or medical information for someone else, (3) buy medicine or vitamins online, (4) look for assistance for the care you provided someone else, (5) use email or the internet to communicate with a doctor or doctor's office, (6) track health care costs/changes, or (7) look up medical tests. This study identified disparities in eHealth usage across social and demographic characteristics. Particularly, education and income were positively correlated with eHealth score, with participants with higher levels of education and those with higher incomes having increased scores for eHealth usage. However, the same study observed that age and Hispanic ethnicity were negatively correlated with eHealth score, such that older patients had lower scores of eHealth usage, and Hispanics also had lower scores of eHealth usage [31]. Low eHealth usage among individuals of Hispanic ethnicity may be due to low English proficiency and lower levels of health literacy [32,33]. Among older individuals, lower levels of health literacy and technological skill have been found to be associated with lower eHealth usage [34,35]. A previous study examining associations between health literacy and health information seeking found that participants with chronic conditions were more likely to be engaged in health information seeking and higher instances of seeking care based on information found on the Web. Additionally, participants with chronic conditions had higher eHealth literacy scores compared to participants without chronic conditions [36]. When compared to patients without chronic health conditions, patients with a history of chronic conditions reported frequent use of patient portals for different aspects of health care delivery such as checking lab reports, messaging their doctors, and setting up appointments [36]. However, this study failed to adjust for social and demographic factors that are associated with both chronic disease status and health information seeking 
behaviors. While many studies have looked at disparities in the usage of patient portals in patients with specific chronic conditions, no studies thus far have looked at disparities in the usage of patient portals in only people with chronic conditions in a nationallyrepresentative sample of the noninstitutionalized US population. As EHR usage has been associated with significant improvements in patient self-management of chronic diseases, as well as improved quality of care given by providers, understanding disparities in EHR use may provide important insights into health care disparities among adults living with chronic health conditions in the US [37].

\section{Materials and Methods}

The National Cancer Institute's Health Information National Trends Survey (HINTS) is a publicly available national representative survey of the noninstitutionalized adult population that collects data about Americans' use of cancer related information. Data for this study came from the HINTS 5 cycle $1(N=3335)$, collected from January 2017 to May 2017, and HINTS 5 cycle $2(N=3504)$, collected from January 2018 to May 2018. The sampling design for the HINTS survey has been described extensively [22,38]. The response rate was $32.4 \%$ for HINTS 5 cycle 1 and $32.985 \%$ for HINTS 5 cycle 2.

The goal of this study was to assess differences in EHR usage among respondents with chronic diseases conditions. Using self-reported data, the study was restricted to respondents with any of the following conditions: diabetes, hypertension, lung disease, heart conditions, depression, cancer, and arthritis. The final analytic sample was further restricted to respondents who reported accessing their online medical record at least once in the past 12 months for various reasons ( $N=736$ and 816 respectively) for a total sample size of 1552. The outcomes of EHR usage were assessed using 4 HINTS questions relating to the purposes of accessing the online medical record to (1) securely message their health care provider, (2) request a refill of medications, (3) make a decision on how to treat illness or condition, and (4) securely share it with another provider.

Primary predictors of interest were gender, race/ethnicity, age, education, income, multimorbidity, and nativity status. The covariates of interest were smoking status, employment status, regular access to a health care provider, insurance status, general health status, and family history of cancer. To measure the change in EHR use across the two HINTS releases, we used a dummy-coded variable to represent the survey year.

We used multivariable regression models to find patterns of associations of sociodemographic characteristics with domains of eHealth usage in the population of US patients with chronic conditions who have access to their online records. The use of online records to securely message health care providers in the past 12 months and the use of online records to request prescription refills in the past 12 months were analyzed using Poisson regression with a log link and robust estimates of standard errors [39]. The use of online records to make decisions on how to treat an illness or condition in the past 12 months and the use of online records to securely share health records with another provider in the past 12 months were analyzed using logistic regression. To account for the complex survey design used to collect the data, we used jackknife replicate weights to compute accurate standard errors, with all analyses weighted to provide nationally representative estimates. We conducted all statistical analyses using SAS $9.4^{\circledR}$ and Stata $16^{\circledR}$. The threshold for the significance of the $p$-value was set to $\leq 0.05$.

We summarized the data using appropriate descriptive statistics such as frequency (percent) and weighted percent (standard error). We presented the multivariable regression models using incident rate ratios (IRR) and odds ratio (OR) with a 95\% confidence interval $(\mathrm{CI})$.

\section{Results}

3.1. Descriptive Results

The final analytic sample comprising respondents with at least one chronic condition that accessed their online medical record at least once in the past 12 months resulted in 
1552 participants from the two HINTS cycles. We have presented the summary of the sociodemographic characteristics of the respondents in Table 1 . The analytic sample was $56 \%$ female, $42 \% 18-49$ years old, $70 \%$ non-Hispanic White, $78.2 \%$ with some college education, $58 \%$ employed, and $47.2 \%$ with an income of $\$ 75,000$ or more. We combined Asian and other races for the purpose of the multivariable analysis. The sample analyzed was $88.8 \%$ US born, and 93\% reported speaking English very well. Additionally, $96.4 \%$ had access to health insurance, $83 \%$ had a regular health care provider, and over $73 \%$ of the participants reported having a family history of cancer.

Table 1. Sociodemographic characteristics of HINTS respondents with at least one chronic condition who accessed their patient portal at least once in the past 12 months $(N=1552)$.

\begin{tabular}{|c|c|c|c|}
\hline $\begin{array}{l}\text { Sociodemographic } \\
\text { Characteristics }\end{array}$ & $n$ & Unweighted Percent & $\begin{array}{l}\text { Weighted Percent } \\
\text { (SE) }\end{array}$ \\
\hline \multicolumn{4}{|l|}{ Age } \\
\hline $18-34$ & 120 & 7.73 & $14.53(1.88)$ \\
\hline $35-49$ & 301 & 19.39 & $28.20(2.01)$ \\
\hline $50-64$ & 579 & 37.31 & 35.10 (1.78) \\
\hline $65-74$ & 376 & 24.23 & $13.91(0.84)$ \\
\hline$\geq 75$ & 147 & 9.47 & $6.98(0.72)$ \\
\hline Missing & 29 & 1.87 & $1.27(0.29)$ \\
\hline \multicolumn{4}{|l|}{ Gender } \\
\hline Male & 554 & 35.70 & $40.46(1.79)$ \\
\hline Female & 917 & 59.09 & 55.59 (1.80) \\
\hline Missing & 81 & 5.22 & $3.95(0.71)$ \\
\hline \multicolumn{4}{|l|}{ Race/Ethnicity } \\
\hline $\begin{array}{l}\text { Non-Hispanic } \\
\text { White }\end{array}$ & 1036 & 66.75 & $70.13(1.59)$ \\
\hline $\begin{array}{l}\text { Non-Hispanic } \\
\text { Black }\end{array}$ & 178 & 11.47 & $7.92(0.77)$ \\
\hline Hispanic & 136 & 8.76 & $11.48(1.24)$ \\
\hline Asian & 51 & 3.29 & $3.63(0.77)$ \\
\hline Other & 60 & 3.87 & $2.95(0.57)$ \\
\hline Missing & 91 & 5.86 & $3.88(0.65)$ \\
\hline \multicolumn{4}{|l|}{ Education } \\
\hline $\begin{array}{l}\text { High school or } \\
\text { Less }\end{array}$ & 226 & 14.56 & $20.64(1.58)$ \\
\hline $\begin{array}{l}\text { Some College or } \\
\text { More }\end{array}$ & 1307 & 84.21 & $78.24(1.61)$ \\
\hline Missing & 19 & 1.22 & $1.12(0.39)$ \\
\hline \multicolumn{4}{|l|}{ Employment } \\
\hline Employed & 811 & 52.26 & $58.18(1.92)$ \\
\hline Unemployed & 722 & 46.52 & 41.12 (1.93) \\
\hline Missing & 19 & 1.22 & $0.71(0.21)$ \\
\hline \multicolumn{4}{|l|}{ Income } \\
\hline Less than $\$ 20,000$ & 131 & 8.44 & $8.53(1.11)$ \\
\hline $\begin{array}{l}\quad \$ 20,000 \text { to } \\
<\$ 35,000\end{array}$ & 144 & 9.28 & $8.05(1.07)$ \\
\hline $\begin{aligned} & \$ 35,000 \text { to } \\
< & \$ 50,000\end{aligned}$ & 174 & 11.21 & $11.51(1.28)$ \\
\hline $\begin{array}{l}\$ 50,000 \text { to } \\
<\$ 75,000\end{array}$ & 296 & 19.07 & $18.23(1.43)$ \\
\hline$\$ 75,000$ or More & 682 & 43.94 & $47.19(1.98)$ \\
\hline Missing & 125 & 8.05 & $6.49(0.74)$ \\
\hline
\end{tabular}


Table 1. Cont.

\begin{tabular}{lccc}
\hline $\begin{array}{l}\text { Sociodemographic } \\
\text { Characteristics }\end{array}$ & $n$ & Unweighted Percent & $\begin{array}{c}\text { Weighted Percent } \\
\text { (SE) }\end{array}$ \\
\hline $\begin{array}{l}\text { Born in the United States } \\
\text { Yes }\end{array}$ & 1373 & 88.47 & $88.81(1.25)$ \\
No & 158 & 10.18 & $10.41(1.27)$ \\
Missing & 21 & 1.35 & $0.78(0.22)$ \\
Health Insurance & & & \\
$\quad$ Yes & 1512 & 97.42 & $96.35(1.01)$ \\
No & 30 & 1.93 & $3.34(1.01)$ \\
Missing & 10 & 0.64 & $0.31(0.13)$ \\
Regular Provider & & & $82.89(1.56)$ \\
Yes & 1325 & 85.37 & $15.81(1.53)$ \\
No & 212 & 13.66 & $1.30(0.54)$ \\
Missing & 15 & 0.97 & $73.89(1.91)$ \\
Family History of Cancer & & & $24.76(1.88)$ \\
Yes & 1174 & 75.64 & $1.35(0.32)$ \\
No & 348 & 22.42 & \\
Missing & 30 & 1.93 & $47.95(1.92)$ \\
HINTS 5 Survey & & & $52.05(1.92)$ \\
Cycle 1 & 736 & 47.42 & \\
Cycle 2 & 816 & 52.58 & \\
\hline
\end{tabular}

SE: Standard Error.

Table 2 presents the clinical characteristics of the respondents. About $59 \%$ of the analytic sample were never smokers. Overall estimates suggest that about $56 \%$ of respondents reported having more than one chronic condition. Within the analytic sample, the most prevalent chronic condition was high blood pressure, with $55 \%$ of the respondents reporting having high blood pressure. However, about $45 \%$ reported being in very good or excellent health, and less than $20 \%$ reported being in fair or poor health.

Table 2. The Clinical characteristics of HINTS respondents with at least one chronic condition who accessed their patient portal at least once in the past 12 months $(N=1552)$.

\begin{tabular}{lccc}
\hline $\begin{array}{c}\text { Clinical } \\
\text { Characteristics }\end{array}$ & $n$ & Unweighted Percent & $\begin{array}{c}\text { Weighted Percent } \\
\text { (SE) }\end{array}$ \\
\hline General Health & & & \\
Excellent & 132 & 8.51 & $8.12(0.89)$ \\
Very Good & 607 & 39.11 & $37.13(1.97)$ \\
Good & 557 & 35.89 & $39.09(1.98)$ \\
Fair & 207 & 13.34 & $13.46(1.18)$ \\
Poor & 40 & 2.58 & $2.62(0.57)$ \\
Missing & 9 & 0.58 & $0.57(0.22)$ \\
Smoking Status & & & \\
Current & 152 & 9.79 & $11.67(1.21)$ \\
Former & 471 & 30.35 & $29.45(1.52)$ \\
Never & 912 & 58.76 & $57.90(1.94)$ \\
Diabetes & & & \\
Yes & 423 & 27.26 & $24.70(1.52)$ \\
No & 1119 & 72.10 & $74.66(1.53)$ \\
Missing & 10 & 0.64 & $0.65(0.29)$ \\
High Blood Pressure & & & \\
Yes & 884 & 56.96 & $54.87(1.95)$ \\
No & 654 & 42.14 & $44.45(1.99)$ \\
Missing & 14 & 0.90 & $0.68(0.25)$ \\
\hline
\end{tabular}


Table 2. Cont.

\begin{tabular}{|c|c|c|c|}
\hline $\begin{array}{c}\text { Clinical } \\
\text { Characteristics }\end{array}$ & $n$ & Unweighted Percent & $\begin{array}{c}\text { Weighted Percent } \\
\text { (SE) }\end{array}$ \\
\hline \multicolumn{4}{|l|}{ Lung Disease } \\
\hline Yes & 272 & 17.53 & $15.95(1.30)$ \\
\hline No & 1273 & 82.02 & $83.76(1.29)$ \\
\hline Missing & 7 & 0.45 & $0.29(0.13)$ \\
\hline \multicolumn{4}{|l|}{ Heart Conditions } \\
\hline Yes & 195 & 12.56 & $11.26(1.37)$ \\
\hline No & 1349 & 86.92 & $88.43(1.37)$ \\
\hline Missing & 8 & 0.52 & $0.31(0.12)$ \\
\hline \multicolumn{4}{|l|}{ Depression } \\
\hline Yes & 547 & 35.24 & $39.88(1.76)$ \\
\hline No & 997 & 64.24 & $59.87(1.76)$ \\
\hline Missing & 8 & 0.52 & $0.25(0.11)$ \\
\hline \multicolumn{4}{|l|}{ Arthritis } \\
\hline Yes & 621 & 40.01 & $33.84(1.45)$ \\
\hline No & 925 & 59.60 & $65.83(1.46)$ \\
\hline Missing & 6 & 0.39 & $0.33(0.19)$ \\
\hline \multicolumn{4}{|l|}{ Cancer } \\
\hline Yes & 357 & 23.00 & $14.96(1.08)$ \\
\hline No & 1192 & 76.80 & $84.98(1.09)$ \\
\hline Missing & 3 & 0.19 & $0.05(0.03)$ \\
\hline \multicolumn{4}{|l|}{ Multimorbidity } \\
\hline Yes & 958 & 61.73 & $56.03(1.72)$ \\
\hline No & 594 & 38.27 & $43.97(1.72)$ \\
\hline
\end{tabular}

SE: Standard Error.

We have presented the summary for the outcome variables in Table 3. Of all the respondents who accessed their medical records in the past 12 months, $47.3 \%$ of the participants used it 1-2 times, while less than $10 \%$ accessed their medical record 10 or more times. In the EHR communication domains, $48 \%$ of the respondents used the online medical record system to securely message their health care provider, $43.8 \%$ of the participants used the online medical record system to request a refill of medications, $21.1 \%$ of the respondents used their online medical record system to make a decision on how to treat an illness or condition, and $12 \%$ securely shared their medical record with another provider.

Table 3. Summary statistics of patient portal-related communication $(N=1552)$.

\begin{tabular}{|c|c|c|c|}
\hline $\begin{array}{l}\text { Use of Online } \\
\text { Medical Record }\end{array}$ & $n$ & $\begin{array}{l}\text { Unweighted } \\
\text { Percent }\end{array}$ & $\begin{array}{c}\text { Weighted } \\
\text { Percent (SE) }\end{array}$ \\
\hline $\begin{array}{l}\text { Number of times you } \\
\text { accessed your record } \\
\text { online in the past } 12 \\
\text { months? }\end{array}$ & & & \\
\hline $1-2$ times & 695 & 44.78 & $47.27(1.92)$ \\
\hline 3-5 times & 523 & 33.70 & $32.94(1.90)$ \\
\hline $6-9$ times & 172 & 11.08 & $10.09(0.94)$ \\
\hline 10 times or more & 162 & 10.44 & $9.70(1.05)$ \\
\hline $\begin{array}{l}\text { Used online record to } \\
\text { securely message a } \\
\text { health care provider } \\
\text { in the past } 12 \text { months }\end{array}$ & & & \\
\hline Yes & 750 & 48.32 & $50.05(2.03)$ \\
\hline No & 742 & 47.81 & $46.47(2.04)$ \\
\hline Missing & 60 & 3.87 & $3.48(0.63)$ \\
\hline
\end{tabular}


Table 3. Cont.

\begin{tabular}{|c|c|c|c|}
\hline $\begin{array}{l}\text { Use of Online } \\
\text { Medical Record }\end{array}$ & $n$ & $\begin{array}{l}\text { Unweighted } \\
\text { Percent }\end{array}$ & $\begin{array}{c}\text { Weighted } \\
\text { Percent (SE) }\end{array}$ \\
\hline \multicolumn{4}{|l|}{$\begin{array}{l}\text { Used online record to } \\
\text { request a refill of } \\
\text { medications in the } \\
\text { past } 12 \text { months }\end{array}$} \\
\hline Yes & 680 & 43.81 & 42.07 (1.97) \\
\hline No & 820 & 52.84 & $54.75(1.96)$ \\
\hline Missing & 52 & 3.35 & $3.17(0.61)$ \\
\hline \multicolumn{4}{|c|}{$\begin{array}{l}\text { Used online record to } \\
\text { make a decision on } \\
\text { how to treat illness or } \\
\text { condition in the past } \\
12 \text { months }\end{array}$} \\
\hline Yes & 327 & 21.07 & $20.81(1.62)$ \\
\hline No & 1170 & 75.39 & $75.89(1.70)$ \\
\hline Missing & 55 & 3.54 & $3.30(0.61)$ \\
\hline \multicolumn{4}{|l|}{$\begin{array}{l}\text { Used online record to } \\
\text { securely share it with } \\
\text { another provider in } \\
\text { the past } 12 \text { months }\end{array}$} \\
\hline Yes & 186 & 11.98 & $12.02(1.15)$ \\
\hline No & 1314 & 84.66 & $84.79(1.21)$ \\
\hline Missing & 52 & 3.35 & $3.19(0.62)$ \\
\hline
\end{tabular}

SE: Standard Error.

\subsection{Multivariable Model}

We have presented the results of the multivariable model in Table 4. Among HINTS respondents with chronic conditions who accessed their online medical record at least once in the past 12 months, respondents 65 to 74 years and those 75 years or older were significantly less likely to use the system to securely message their health care providers compared to respondents 18 to 34 years $(\mathrm{IRR}=0.73,95 \% \mathrm{CI}=0.57,0.94$; and $\mathrm{IRR}=0.54$, $95 \% \mathrm{CI}=0.35,0.83$ ) respectively.

Table 4. Multivariable Model for Patient Portal-related Communication $(N=1552)$.

\begin{tabular}{|c|c|c|c|c|c|c|c|c|}
\hline \multirow[t]{2}{*}{$\begin{array}{l}\text { Sociodemographic } \\
\text { Characteristics }\end{array}$} & \multicolumn{2}{|c|}{$\begin{array}{l}\text { Securely Message } \\
\text { Provider in the } \\
\text { Past } 12 \text { Months }\end{array}$} & \multicolumn{2}{|c|}{$\begin{array}{c}\text { Request } \\
\text { PrescriptionRefills in the } \\
\text { Past } 12 \text { Months }\end{array}$} & \multicolumn{2}{|c|}{$\begin{array}{l}\text { Make a Decision on } \\
\text { How to Treat } \\
\text { Condition in the } \\
\text { Past } 12 \text { Months }\end{array}$} & \multicolumn{2}{|c|}{$\begin{array}{l}\text { Securely Share it with } \\
\text { Other Providers in the } \\
\text { Past } 12 \text { Months }\end{array}$} \\
\hline & IRR & $95 \%$ CI & IRR & $95 \%$ CI & OR & $95 \%$ CI & OR & $95 \%$ CI \\
\hline \multicolumn{9}{|l|}{ Race/Ethnicity } \\
\hline $\begin{array}{l}\text { Non-Hispanic } \\
\text { White }\end{array}$ & 1.00 & $1.00,1.00$ & 1.00 & $1.00,1.00$ & 1.00 & $1.00,1.00$ & 1.00 & $1.00,1.00$ \\
\hline $\begin{array}{l}\text { Non-Hispanic } \\
\text { Black }\end{array}$ & 0.94 & $0.71,1.25$ & 1.11 & $0.84,1.49$ & 1.46 & $0.77,2.79$ & 1.85 & $0.84,4.07$ \\
\hline Hispanic & 0.84 & $0.62,1.13$ & 0.99 & $0.71,1.37$ & 1.08 & $0.41,2.88$ & 0.79 & $0.25,2.45$ \\
\hline Other & 1.09 & $0.79,1.50$ & 1.10 & $0.75,1.60$ & 2.64 & $1.12,6.24$ * & 3.61 & $1.25,10.42$ * \\
\hline \multicolumn{9}{|l|}{ Age } \\
\hline $18-34$ & 1.00 & $1.00,1.00$ & 1.00 & $1.00,1.00$ & 1.00 & $1.00,1.00$ & 1.00 & $1.00,1.00$ \\
\hline $35-49$ & 0.98 & $0.77,1.26$ & 1.08 & $0.68,1.72$ & 0.93 & $0.37,2.35$ & 0.80 & $0.30,2.13$ \\
\hline $50-64$ & 0.77 & $0.58,1.01$ & 1.08 & $0.70,1.68$ & 0.49 & $0.19,1.25$ & 0.48 & $0.18,1.28$ \\
\hline $65-74$ & 0.73 & $0.57,0.94$ * & 1.06 & $0.64,1.74$ & 0.30 & $0.11,0.84$ * & 0.34 & $0.09,1.22$ \\
\hline$\geq 75$ & 0.54 & $0.35,0.83^{* *}$ & 1.14 & $0.65,2.01$ & 0.70 & $0.22,2.16$ & 0.17 & $0.03,0.99 *$ \\
\hline \multicolumn{9}{|l|}{ Gender } \\
\hline Male & 1.00 & $1.00,1.00$ & 1.00 & $1.00,1.00$ & 1.00 & $1.00,1.00$ & 1.00 & $1.00,1.00$ \\
\hline Female & 0.99 & $0.83,1.18$ & 0.83 & $0.68,1.02$ & 1.02 & $0.61,1.71$ & 0.99 & $0.55,1.79$ \\
\hline
\end{tabular}


Table 4. Cont.

\begin{tabular}{|c|c|c|c|c|c|c|c|c|}
\hline \multirow[t]{2}{*}{$\begin{array}{l}\text { Sociodemographic } \\
\text { Characteristics }\end{array}$} & \multicolumn{2}{|c|}{$\begin{array}{l}\text { Securely Message } \\
\text { Provider in the } \\
\text { Past } 12 \text { Months }\end{array}$} & \multicolumn{2}{|c|}{$\begin{array}{l}\text { Request } \\
\text { PrescriptionRefills in the } \\
\text { Past } 12 \text { Months }\end{array}$} & \multicolumn{2}{|c|}{$\begin{array}{l}\text { Make a Decision on } \\
\text { How to Treat } \\
\text { Condition in the } \\
\text { Past } 12 \text { Months }\end{array}$} & \multicolumn{2}{|c|}{$\begin{array}{l}\text { Securely Share it with } \\
\text { Other Providers in the } \\
\text { Past } 12 \text { Months }\end{array}$} \\
\hline & IRR & $95 \%$ CI & IRR & $95 \%$ CI & OR & $95 \% \mathrm{CI}$ & OR & $95 \%$ CI \\
\hline Education & & & & & & & & \\
\hline $\begin{array}{c}\text { High } \\
\text { School or Less }\end{array}$ & 0.87 & $0.67,1.14$ & 0.87 & $0.64,1.19$ & 1.03 & $0.47,2.27$ & 0.67 & $0.26,1.73$ \\
\hline $\begin{array}{l}\text { Some } \\
\text { College } \\
\text { College }\end{array}$ & 1.00 & $0.82,1.21$ & 0.95 & $0.75,1.22$ & 0.91 & $0.50,1.65$ & 1.02 & $0.50,2.07$ \\
\hline $\begin{array}{l}\text { Graduate or } \\
\text { More } \\
\text { Income }\end{array}$ & 1.00 & $1.00,1.00$ & 1.00 & $1.00,1.00$ & 1.00 & $1.00,1.00$ & 1.00 & $1.00,1.00$ \\
\hline $\begin{array}{l}\text { Less than } \\
\$ 20,000\end{array}$ & 0.87 & $0.59,1.29$ & 0.73 & $0.43,1.25$ & 1.14 & $0.39,3.31$ & 0.37 & $0.12,1.18$ \\
\hline $\begin{array}{l}\quad \$ 20,000 \text { to } \\
<\$ 35,000\end{array}$ & 0.75 & $0.52,1.10$ & 1.14 & $0.76,1.71$ & 0.85 & $0.34,2.12$ & 0.72 & $0.27,1.93$ \\
\hline $\begin{array}{l}\quad \$ 35,000 \text { to } \\
<\$ 50,000\end{array}$ & 0.62 & $0.44,0.86^{* *}$ & 1.00 & $0.73,1.35$ & 1.56 & $0.69,3.53$ & 1.39 & $0.45,4.35$ \\
\hline $\begin{array}{l}\quad \$ 50,000 \text { to } \\
<\$ 75,000\end{array}$ & 0.99 & $0.78,1.26$ & 0.98 & $0.74,1.31$ & 1.03 & $0.51,2.06$ & 0.79 & $0.36,1.73$ \\
\hline $\begin{array}{l}\quad \$ 75,000 \text { or } \\
\text { More } \\
\text { Born in the } \\
\text { United States }\end{array}$ & 1.00 & $1.00,1.00$ & 1.00 & $1.00,1.00$ & 1.00 & $1.00,1.00$ & 1.00 & $1.00,1.00$ \\
\hline Yes & 1.00 & $1.00,1.00$ & 1.00 & $1.00,1.00$ & 1.00 & $1.00,1.00$ & 1.00 & $1.00,1.00$ \\
\hline No & 0.92 & $0.68,1.23$ & 0.74 & $0.50,1.08$ & 0.59 & $0.27,1.28$ & 0.81 & $0.30,2.16$ \\
\hline Multimorbidity & & & & & & & & \\
\hline Yes & 0.93 & $0.78,1.11$ & 1.20 & $0.97,1.48$ & 1.48 & $0.86,2.57$ & 2.04 & $1.16,3.59$ * \\
\hline No & 1.00 & $1.00,1.00$ & 1.00 & $1.00,1.00$ & 1.00 & $1.00,1.00$ & 1.00 & $1.00,1.00$ \\
\hline $\begin{array}{l}\text { HINTS } 5 \\
\text { Survey }\end{array}$ & & & & & & & & \\
\hline Cycle 1 & 1.00 & $1.00,1.00$ & 1.00 & $1.00,1.00$ & 1.00 & $1.00,1.00$ & 1.00 & $1.00,1.00$ \\
\hline Cycle 2 & 1.17 & $1.00,1.36^{*}$ & 1.07 & $0.88,1.30$ & 1.99 & $1.23,3.20 * *$ & 1.28 & $0.77,2.11$ \\
\hline
\end{tabular}

The multivariable regression model (logistic and Poisson) was adjusted for insurance status, employment status, having a regular provider, general health status, smoking status, and family history of cancer. We present the results of the Poisson regression models as incident rate ratios (IRR) and the results of the logistic regression models as odds ratio (OR) with $95 \%$ confidence interval (CI). ${ }^{*} p$-value $\leq 0.05,{ }^{* *} p$-value $\leq 0.01$.

The results of the multivariable model indicate that race, age, and survey years are associated with respondents who reported the use of the online medical record to make a decision about treating a condition or an illness. Respondents in the 65 to 74 age range had reduced odds of using the medical record to make a decision regarding treating a condition or illness $(\mathrm{OR}=0.30,95 \% \mathrm{CI}=0.11,0.84)$. There was a significant increase in the use of the online medical record to make a decision on how to treat a condition or illness from HINTS 5 cycle 1 to HINTS 5 cycle $2(\mathrm{OR}=1.99,95 \% \mathrm{CI}=1.23,3.20)$. Additionally, respondents in the other racial category had increased odds of using the online medical record to make decisions on how to treat a condition or illness in the past 12 months ( $\mathrm{OR}=$ $2.64,95 \% \mathrm{CI}=1.12,6.24)$.

Those in the 75 years and older age range had reduced odds of securely sharing their online record with another provider compared to respondents aged 18 to 34 years $(\mathrm{OR}=0.17,95 \% \mathrm{CI}=0.03,0.99)$. Respondents with multimorbidity ( 2 or more diagnoses $)$ had significantly increased odds of securely sharing their online record with another provider in the past 12 months $(\mathrm{OR}=2.04,95 \% \mathrm{CI}=1.16,3.59)$. Lastly, respondents in the other racial category had increased odds of securely sharing their online medical record 
with another provider in the past 12 months compared to Non-Hispanic Whites (OR $=3.61$, $95 \% \mathrm{CI}=1.25,10.42)$.

The sociodemographic characteristics of the respondents were not associated with their likelihood of requesting prescription refills using the online medical record. No other predictors of interest were significantly associated with any of the outcomes after adjustment for covariates.

\section{Discussion}

To our knowledge, this is the first study to examine disparities in accessing patient portals for disease management among chronically ill noninstitutionalized adults using nationally representative data. Our study examined a broad range of reasons for the use patient portals for disease management, including secure messaging with providers, requesting medications refills, and sharing medical records with other providers.

Our study is consistent with previous studies examining eHealth communication in US adults, revealing that age disparities exist in the use of eHealth communication methods, with older participants having a lower rate of eHealth communication across multiple domains $[26,27,29,40]$. However, our study yielded specific insights into the use of the patient portals, while the other studies were focused on the more general use of the eHealth domain of communication, such as personal email, searching for health information, buying medications online, and sharing health content though social networking sites $[26,27,29,40]$. Other studies of seniors 65-79 years old revealed that patients aged 70 years and older were less likely to register to use web portals $[24,25]$. Some potential explanations as to why older respondents were less likely to be engaged in use of the patient portals include the accessibility of the patient portals, safety concerns, and the usefulness of the portal for communication as opposed to face-to-face meetings with providers. This result, however, is concerning, as the likelihood of using the patient portal may be reflective of the ability to use telehealth services, and because the COVID-19 pandemic has accelerated the expansion of telehealth services [41]. Since a recent study of older adults' readiness to engage in eHealth and mHealth indicated that over $80 \%$ of the respondents reported having access to the internet at home, and $44 \%$ of those using the internet reported doing so on a mobile device [42], further studies should be done to understand the digital divide for older patients and how to engage them in eHealth.

In a prior HINTS study of HRIU use among cancer survivors, there has been an increasing trend in the use of HRIU [21,43]. In our study, we similarly found an increase in the use of EHR to make clinical decisions about how to treat an illness or condition. However, no increasing trend was noted in any of the other domains analyzed. This result underscores the importance of encouraging and promoting the use of the portal for other aspects of chronic disease management, particularly communicating with providers and sharing medical records with other providers. Despite the increasing trend in HRIU among cancer survivors, in a prior HINTS study of cancer survivors, there were age, race, education, and geographic disparities in the use of HRIU [27,44]. This study is in line with our result of lower use of online medical records for secure communication, to treat medical conditions, and to share with other providers among older participants. With the recent COVID-19 pandemic, health care providers have shifted to the use of telehealth for primary and specialty care for disease management [45]. The shift to telehealth during the pandemic could further widen the gap of health outcomes for patients with low and limited access to technology and those who are not ready to adopt new or emerging technologies.

Our study indicates that respondents with two or more chronic conditions were 2.04 times more likely to share the EHR with another provider. This result may be attributed to the need for different specialists to be involved in the care of patients with multimorbidity. This current finding is somewhat in line with other study that indicated that patients with chronic conditions were more engaged in care-seeking behavior based on health-related internet searches [36]. Patients with multimorbidity should be encouraged to participate in other forms of eHealth communication through the patient portal for disease management. 
Prior studies have found sociodemographic disparities in the use of HRIU [23,28,29,46]. In our study, those identified as other race (Asian and others) were significantly more likely than those identified as White to use the portal for clinical decision making and transferring medical records to another provider. However, only $3.63 \%$ of the participants self-identified as Asian, and only $2.95 \%$ identified as other, limiting any form of generalization of the results. Although sociodemographic disparities exist in who is being offered access to EHR [47], in our study, which focused on only respondents who reported accessing their EHR at least once in the preceding 12 months, characteristics such as income and education level were not associated with the different domain of using EHR. We suspect that the result is due to our restriction of the analytic sample to respondents who reported having accessed the web portal at least once in the past 12 months. This subset of respondents is important because those respondents were not only offered access to their EHR, but have indicated using it. This restriction on the inclusion criteria for the final analytic sample could potentially control for some of the disparities that exist in accessing EHR, such as access to and use of the internet [26], and being offered its use [47]. For that reason, we did not adjust for the access/use of internet because using the web portal is an indication of internet access/usage.

\section{Study Strengths and Limitations}

There are several strengths to this study. First, the HINTS survey is a national survey of adults in the United States 18 and older. Thus, the subsample used in this study represents adults in the United States living with chronic conditions who have accessed their online health portal at least once in the past 12 months. We also used two HINTS cycles, allowing us to see changes in the use of EHR over time. Additionally, the study included an exploration of different reasons for using the EHR in disease management.

Despites the strengths, our study has some limitations. Given that HINTS is a crosssectional study, we cannot make conclusions about causality. Furthermore, the survey has participants with a limited number of chronic conditions. Therefore, we can assess the association of respondents' characteristics with reasons for using EHR only in a subset of patients with chronic conditions. Future iterations of the survey should ask participants about other prevalent chronic conditions. In addition, future iterations of HINTS should include questions that address barriers to using the online medical records.

\section{Conclusions}

A recent HINTS brief indicated that the proportion of US adults accessing their online medical records increased from $27 \%$ in 2014 to $40 \%$ in 2018 [48]. Despite the increase in the access and use of EHR, our study reveals age as a factor of disparity in assessing the EHR for health care management. However, past studies have shown that over $80 \%$ of older adults are already using the internet, and $44 \%$ have access to smartphones. Therefore, health care providers should develop strategies to inform older patients and their proxies about the accessibility of the EHR as a secure means of communication to providers. Some strategies can include the development of user-friendly patient portals for multiple platforms that encourage greater use. Other strategies should include eHealth literacy programs that address patients' concerns regarding safeguarding their protected health information. Additional technological improvements may include the use of integrated displays to decrease user cognitive load [49-51], integration of linked EHR records at the household level to facilitate delivery of services, and embedding of health literacy tools (e.g., embedded medical search engines, integrated AI voice chatbots for on-demand self-care advice) to facilitate meaningful patient engagement.

The use of electronic patient portals raises challenges and ethical issues regarding older adults. Notably, disparities in internet access, a key factor for the use of e-health, persist among underserved populations such as older adults and individuals of lower socioeconomic status [52,53]. Older adults may encounter more challenges in the use of EHR and electronic patient portals because older generations must learn and acquire the 
necessary skills needed to navigate the internet and are less comfortable using technology compared to their counterparts. Furthermore, some older adults with certain illnesses may require support to navigate the complexities of eHealth portals [54]. Our findings are consistent with prior work using HINTS data, which showed that older US adults were less likely to engage in eHealth, and point to a need for additional support to ensure equitable access to e-health for older adults [22]. Other ethical aspects that are of importance are autonomy, privacy, confidentiality, consent, and beneficence [55]. Those ethical issues can be extended to the adaptability and accessibility of patient portals for personal use by patients. With older participants being less likely to engage in eHealth communication through the patient portal, adopters of EHR should consider the issue of autonomy, privacy, confidentiality, and equality of access as they encourage older patients and their proxies to make full use of the system for disease management.

Author Contributions: Conceptualization, R.C. and M.C.-R.; methodology, R.C and M.C.-R.; software, R.C.; formal analysis, R.C.; investigation, R.C., S.I., Z.T.O., A.R., and M.C.-R.; resources, R.C., S.I., and M.C.-R.; data curation, R.C.; writing—original draft preparation, R.C., S.I., Z.T.O., A.R., and M.C.-R.; writing-review and editing, R.C., S.I., Z.T.O., A.R., and M.C.-R.; visualization, R.C. and S.I.; supervision, R.C. and M.C.-R.; project administration, R.C. All authors have read and agreed to the published version of the manuscript.

Funding: This research received no external funding.

Institutional Review Board Statement: Not applicable.

Informed Consent Statement: Not applicable.

Data Availability Statement: The data that support the findings of this study are available from https:/ / hints.cancer.gov/data/download-data.aspx.

Conflicts of Interest: The authors declare no conflict of interest.

\section{References}

1. Jhamb, M.; Cavanaugh, K.L.; Bian, A.; Chen, G.; Ikizler, T.A.; Unruh, M.L.; Abdel-Kader, K. Disparities in electronic health record patient portal use in nephrology clinics. Clin. J. Am. Soc. Nephrol. 2015, 10, 2013-2022. [CrossRef]

2. Rathert, C.; Mittler, J.N.; Banerjee, S.; McDaniel, J. Patient-centered communication in the era of electronic health records: What does the evidence say? Patient Educ. Couns. 2017, 100, 50-64. [CrossRef]

3. Kim, E.; Rubinstein, S.M.; Nead, K.T.; Wojcieszynski, A.P.; Gabriel, P.E.; Warner, J.L. The Evolving Use of Electronic Health Records (EHR) for Research. Semin. Radiat. Oncol. 2019, 29, 354-361. [CrossRef]

4. De Angelis, C.D. The electronic health record: Boon or bust for good patient care? Milbank Q. 2014, 92, 442. [CrossRef]

5. Tome, J.; Ahmed, S.; Fagerlin, A.; Powell, C.; Mourao, M.; Chen, E.; Harrison, S.; Segal, J.; Abdel-Kader, K.; Nunes, J.W. Patient electronic health record portal use and patient-centered outcomes in CKD. Kidney Med. 2021, 3, 231-240.e1. [CrossRef] [PubMed]

6. World Health Organization. Global Status Report on Noncommunicable Diseases 2014; World Health Organization: Geneva, Switzerland, 2014.

7. Freid, V.M.; Bernstein, A.B.; Bush, M.A. Multiple chronic conditions among adults aged 45 and over: Trends over the past 10 years. NCHS Data Brief. 2012, 100, 1-8.

8. van Oostrom, S.H.; Gijsen, R.; Stirbu, I.; Korevaar, J.C.; Schellevis, F.G.; Picavet, H.S.J.; Hoeymans, N. Time Trends in Prevalence of Chronic Diseases and Multimorbidity Not Only due to Aging: Data from General Practices and Health Surveys. PLoS ONE 2016, 11, e0160264. [CrossRef] [PubMed]

9. Ward, B.W.; Schiller, J.S. Peer reviewed: Prevalence of multiple chronic conditions among US adults: Estimates from the National Health Interview Survey, 2010. Prev. Chronic. Dis. 2013, 10, E65. [CrossRef] [PubMed]

10. Erdem, E. Prevalence of chronic conditions among Medicare Part A beneficiaries in 2008 and 2010: Are Medicare beneficiaries getting sicker? Prev. Chronic. Dis. 2014, 11, 130118. [CrossRef]

11. Cassell, A.; Edwards, D.; Harshfield, A.; Rhodes, K.; Brimicombe, J.; Payne, R.; Griffin, S. The epidemiology of multimorbidity in primary care: A retrospective cohort study. Br. J. Gen. Pract. 2018, 68, e245-e251. [CrossRef]

12. Reeves, D.; Pye, S.; Ashcroft, D.M.; Clegg, A.; Kontopantelis, E.; Blakeman, T.; van Marwijk, H. The challenge of ageing populations and patient frailty: Can primary care adapt? BMJ 2018, 362, k3349. [CrossRef]

13. Mollica, R.; Gillespie, J. Care Coordination for People with Chronic Conditions; Partnership for Solutions: Portland, ME, USA, 2003.

14. Shakib, S.; Dundon, B.K.; Maddison, J.; Thomas, J.; Stanners, M.; Caughey, G.E.; Clark, R.A. Effect of a Multidisciplinary Outpatient Model of Care on Health Outcomes in Older Patients with Multimorbidity: A Retrospective Case Control Study. PLoS ONE 2016, 11, e0161382. [CrossRef] [PubMed] 
15. Barbabella, F.; Melchiorre, M.G.; Quattrini, S.; Papa, R.; Lamura, G.; Richardson, E.; van Ginneken, E. How Can. eHealth Improve Care for People with Multimorbidity in Europe; World Health Organization, Regional Office for Europe: Copenhagen, Denmark, 2017.

16. Wright, E.; Darer, J.; Tang, X.; Thompson, J.; Tusing, L.; Fossa, A.; Delbanco, T.; Ngo, L.; Walker, J. Sharing Physician Notes Through an Electronic Portal is Associated with Improved Medication Adherence: Quasi-Experimental Study. J. Med. Internet Res. 2015, 17, e226. [CrossRef] [PubMed]

17. Osborn, C.Y.; Mayberry, L.S.; Mulvaney, S.A.; Hess, R. Patient web portals to improve diabetes outcomes: A systematic review. Curr. Diab. Rep. 2010, 10, 422-435. [CrossRef] [PubMed]

18. Kalicki, A.V.; Moody, K.A.; Franzosa, E.; Gliatto, P.M.; Ornstein, K.A. Barriers to telehealth access among homebound older adults. J. Am. Geriatr. Soc. 2021. Epub ahead of print. [CrossRef]

19. Camacho-Rivera, M.; Islam, J.Y.; Rivera, A.; Vidot, D.C. Attitudes toward Using COVID-19 mHealth Tools Among Adults with Chronic Health Conditions: Secondary Data Analysis of the COVID-19 Impact Survey. JMIR Mhealth Uhealth 2020, 8, e24693. [CrossRef]

20. Chou, W.Y.; Hunt, Y.M.; Beckjord, E.B.; Moser, R.P.; Hesse, B.W. Social media use in the United States: Implications for health communication. J. Med. Internet Res. 2009, 11, e48. [CrossRef]

21. Chou, W.Y.; Liu, B.; Post, S.; Hesse, B. Health-related Internet use among cancer survivors: Data from the Health Information National Trends Survey, 2003-2008. J. Cancer Surviv. 2011, 5, 263-270. [CrossRef]

22. Kontos, E.; Blake, K.D.; Chou, W.Y.; Prestin, A. Predictors of eHealth usage: Insights on the digital divide from the Health Information National Trends Survey 2012. J. Med. Internet Res. 2014, 16, e172. [CrossRef]

23. Prestin, A.; Vieux, S.N.; Chou, W.Y. Is Online Health Activity Alive and Well or Flatlining? Findings from 10 Years of the Health Information National Trends Survey. J. Health Commun. 2015, 20, 790-798. [CrossRef]

24. Thackeray, R.; Crookston, B.T.; West, J.H. Correlates of health-related social media use among adults. J. Med. Internet Res. 2013, 15, e21. [CrossRef] [PubMed]

25. Gordon, N.P.; Hornbrook, M.C. Differences in Access to and Preferences for Using Patient Portals and Other eHealth Technologies Based on Race, Ethnicity, and Age: A Database and Survey Study of Seniors in a Large Health Plan. J. Med. Internet Res. 2016, 18, e50. [CrossRef] [PubMed]

26. Hong, Y.A.; Jiang, S.; Liu, P.L. Use of Patient Portals of Electronic Health Records Remains Low from 2014 to 2018: Results from a National Survey and Policy Implications. Am. J. Health Promot. 2020, 34, 677-680. [CrossRef]

27. Jiang, S.; Hong, Y.A.; Liu, P.L. Trends of online patient-provider communication among cancer survivors from 2008 to 2017: A digital divide perspective. J. Cancer Surviv. 2019, 13, 197-204. [CrossRef]

28. Hong, Y.A.; Cho, J. Has the Digital Health Divide Widened? Trends of Health-Related Internet Use among Older Adults From 2003 to 2011. J. Gerontol. B Psychol. Sci. Soc. Sci. 2017, 72, 856-863. [CrossRef]

29. Calixte, R.; Rivera, A.; Oridota, O.; Beauchamp, W.; Camacho-Rivera, M. Social and Demographic Patterns of Health-Related Internet Use Among Adults in the United States: A Secondary Data Analysis of the Health Information National Trends Survey. Int. J. Environ. Res. Public Health 2020, 17, 6856. [CrossRef]

30. Camacho-Rivera, M.; Gonzalez, C.J.; Morency, J.A.; Blake, K.D.; Calixte, R. Heterogeneity in Trust of Cancer Information among Hispanic Adults in the United States: An Analysis of the Health Information National Trends Survey. Cancer Epidemiol. Biomark. Prev. 2020, 29, 1348-1356. [CrossRef]

31. Sherman, L.D.; Patterson, M.S.; Tomar, A.; Wigfall, L.T. Use of digital health information for health information seeking among men living with chronic disease: Data from the health information national trends survey. Am. J. Mens. Health 2020, 14, 1557988320901377. [CrossRef] [PubMed]

32. Millar, R.J.; Sahoo, S.; Yamashita, T.; Cummins, P.A. Literacy skills, language use, and online health information seeking among Hispanic adults in the United States. Patient Educ. Couns. 2020, 103, 1595-1600. [CrossRef] [PubMed]

33. Aponte, J.; Nokes, K.M. Electronic health literacy of older Hispanics with diabetes. Health Promot. Int. 2017, 32, 482-489. [CrossRef] [PubMed]

34. Yamashita, T.; Bardo, A.R.; Cummins, P.A.; Millar, R.J.; Sahoo, S.; Liu, D. The Roles of Education, Literacy, and Numeracy in Need for Health Information during the Second Half of Adulthood: A Moderated Mediation Analysis. J. Health Commun. 2019, 24, 271-283. [CrossRef] [PubMed]

35. Choi, N.G.; Dinitto, D.M. The digital divide among low-income homebound older adults: Internet use patterns, eHealth literacy, and attitudes toward computer/Internet use. J. Med. Internet Res. 2013, 15, e93. [CrossRef]

36. Madrigal, L.; Escoffery, C. Electronic Health Behaviors among US Adults with Chronic Disease: Cross-Sectional Survey. J. Med. Internet Res. 2019, 21, e11240. [CrossRef] [PubMed]

37. Kruse, C.S.; Argueta, D.A.; Lopez, L.; Nair, A. Patient and provider attitudes toward the use of patient portals for the management of chronic disease: A systematic review. J. Med. Internet Res. 2015, 17, e40. [CrossRef]

38. Finney Rutten, L.J.; Davis, T.; Beckjord, E.B.; Blake, K.; Moser, R.P.; Hesse, B.W. Picking up the pace: Changes in method and frame for the health information national trends survey (2011-2014). J. Health Commun. 2012, 17, 979-989. [CrossRef]

39. Zou, G. A modified poisson regression approach to prospective studies with binary data. Am. J. Epidemiol. 2004, 159, 702-706. [CrossRef]

40. Anthony, D.; Campos-Castillo, C. Why Most of Your Patients Aren't Using an Online Portal, and What You Can Do About It. Rhode Isl. Med. J. 2020, 103, 32-34. 
41. Bosworth, A.; Ruhter, J.; Samson, L.W.; Sheingold, S.; Taplin, C.; Tarazi, W.; Zuckerman, R. Medicare Beneficiary Use of Telehealth Visits: Early Data from the Start of COVID-19 Pandemic; Office of the Assistant Secretary for Planning and Evaluation, U.S. Department of Health and Human Services: Washington, DC, USA, 28 July 2020. Available online: https://aspe.hhs.gov/system/ files/pdf/263866/HP_IssueBrief_MedicareTelehealth_final7.29.20.pdf (accessed on 5 August 2020).

42. Gordon, N.P.; Hornbrook, M.C. Older adults' readiness to engage with eHealth patient education and self-care resources: A cross-sectional survey. BMC Health Serv. Res. 2018, 18, 1-13. [CrossRef] [PubMed]

43. Fareed, N.; Swoboda, C.M.; Jonnalagadda, P.; Huerta, T.R. Persistent digital divide in health-related internet use among cancer survivors: Findings from the Health Information National Trends Survey, 2003-2018. J. Cancer Surviv. 2021, 15, 87-98. [CrossRef]

44. Jiang, S.; Liu, P.L. Digital divide and Internet health information seeking among cancer survivors: A trend analysis from 2011 to 2017. Psycho Oncol. 2020, 29, 61-67. [CrossRef] [PubMed]

45. Koonin, L.M.; Hoots, B.; Tsang, C.A.; Leroy, Z.; Farris, K.; Jolly, B.T.; Antall, P.; McCabe, B.; Zelia, C.B.R.; Tong, I.; et al. Trends in the Use of Telehealth During the Emergence of the COVID-19 Pandemic-United States, January-March 2020. MMWR Morb. Mortal. Wkly. Rep. 2020, 69, 1595-1599. [CrossRef]

46. Spooner, K.K.; Salemi, J.L.; Salihu, H.M.; Zoorob, R.J. eHealth patient-provider communication in the United States: Interest, inequalities, and predictors. J. Am. Med. Inform. Assoc. 2017, 24, e18-e27. [CrossRef] [PubMed]

47. Anthony, D.L.; Campos-Castillo, C.; Lim, P.S. Who Isn't Using Patient Portals and Why? Evidence and Implications from A National Sample of US Adults. Health Aff. 2018, 37, 1948-1954. [CrossRef] [PubMed]

48. Health Information National Trend Survey. Trends and Disparities in Patient Portal Use. HINTS Briefs. 2021, 45, 1-2. Available online: https:/ / hints.cancer.gov/docs/Briefs/HINTS_Brief_45.pdf (accessed on 21 June 2021).

49. Curran, R.L.; Kukhareva, P.V.; Taft, T.; Weir, C.R.; Reese, T.J.; Nanjo, C.; Rodriguez-Loya, S.; Martin, D.K.; Warner, P.B.; Shields, D.E.; et al. Integrated displays to improve chronic disease management in ambulatory care: A SMART on FHIR application informed by mixed-methods user testing. J. Am. Med. Inform. Assoc. 2020, 27, 1225-1234. [CrossRef]

50. Brady, K.J.S.; Legler, A.; Adams, W.G. Exploring Opportunities for Household-Level Chronic Care Management Using Linked Electronic Health Records of Adults and Children: A Retrospective Cohort Study. Matern. Child. Health J. 2020, $24,829-836$. [CrossRef]

51. Chen, M.; Decary, M. Embedding Health Literacy Tools in Patient EHR Portals to Facilitate Productive Patient Engagement. Stud. Health Technol. Inform. 2019, 257, 59-63.

52. Serrano, K.; Thai, C.; Greenberg, A.; Blake, K.; Moser, R.; Hesse, B. Progress on Broadband Access to the Internet and Use of Mobile Devices in the United States. Public Health Rep. 2017, 132, 27-31. [CrossRef]

53. Okoye, S.M.; Mulcahy, J.F.; Fabius, C.D.; Burgdorf, J.G.; Wolff, J.L. Neighborhood Broadband and Use of Telehealth among Older Adults: Cross-sectional Study of National Survey Data Linked with Census Data. J. Med. Internet Res. 2021, 23, e26242. [CrossRef] [PubMed]

54. Lam, K.; Lu, A.D.; Shi, Y.; Covinsky, K.E. Assessing Telemedicine Unreadiness Among Older Adults in the United States During the COVID-19 Pandemic. JAMA Intern. Med. 2020, 180, 1389. [CrossRef] [PubMed]

55. Miesperä, A.; Ahonen, S.-M.; Reponen, J. Ethical aspects of eHealth-Systematic review of open access articles. Finn. J. EHealth EWelfare 2013, 5, 165-171. 